\title{
CREATIVITY FOR TOURISM CURRICULA: RESULTS AND IMPLICATIONS
}

\author{
KAMILA PEREDERENKO \\ Turiba University, Faculty of Business Administration, \\ Graudu 68, LV 1058, Riga, Latvia \\ E-mail address: kamila.perederenko@gmail.com
}

\begin{abstract}
Creative specialists are highly demanded in the tourism labour market. This fact is highlighted in the significance of the study on how creativity is fostered in tourism higher education. The objective of this study is to develop a tool for creativity evaluation. In order to attain this objective a literature review to identify underlying variables used to measure creativity has been done. The most significant models and tools have been analysed. The empirical part of the research provides an analysis of the evaluation of creativity needs of Latvian tourism students. This report analyses the findings of the second stage of the research - a questionnaire survey conducted in a well-acknowledged higher education institution in Latvia providing internationally accredited tourism programs. For this stage of the research questionnaires were randomly distributed among local and international students of tourism programs. The results of the study enabled identification of the most significant factors in evaluating creativity.
\end{abstract}

Key words: creativity, tourism higher education, creativity evaluation, curriculum

\section{INTRODUCTION}

Tourism is a significant sector of Latvian economy and a labour provider. Nowadays increased competition faces industry towards a continuous process of quality enhancement. One of the main industry assets is human resources. Due to this fact the development of education and training plays a crucial role. Higher education institutions (HEI) prepare a skilled labour force and contribute to research and innovation growth in the industry. The knowledge-based global economy characterized by the ideas and knowledge exchange and progress of information and technology sets high requirements for higher education. The tourism industry is looking for graduates with domain-specific competencies and high level professional knowledge. Creative specialists are in high demand on the tourism labour market.

Creativity must be developed in students who will be the employees and employers of the next generation. Thus a special attention to fostering innovation and creativity in society by development of higher education has been 
paid in Leuven Communiqué $(2009$, p. 4). This is in line also with the latest documents in European Higher Education Area (EHEA) where the Yerevan Communiqué (2015, p. 2) among other issues highlights creativity and innovation as significant components of the two main goals of higher education in Europe -1) Enhancing the quality and relevance of learning and teaching

and 2) Fostering the employability of graduates throughout their working lives.

OECD Innovation Strategy 2015 maintains the importance of creativity for economic growth (OECD, 2015, p. 7). It stresses the fact that innovation is characterised also by a skilled workforce that can generate new ideas and technologies, bring them to the market and implement them in the workplace, and which is able to adapt to technological and structural changes across society. Moreover, it is pointed out that broad curricula, updated pedagogical practices and the development of tools to assess innovation-related skills are all important in initial education and beyond subject-specific expertise, tertiary education should also develop students' creativity, critical thinking, entrepreneurship and communication (OECD, 2015, p. 13).

The studies regarding curricula design and development according to industry requirements have been conducted ubiquitously. Just last year such studies have been implemented in the USA (Khan, \& Law, 2015), Malaysia (Saleh, Hashim, Yaacob, \& Kashim, 2015), Australia (Johnson, Veitch, \& Devianti, 2015) and the UK (Tom-Lawyer, 2015). Tourism higher education curricula facing industry development challenges analysed in the Czech Republic (Kiralova, 2014) and Latvia (Luka, \& Donina, 2012). Kiralova (2014, p. 1-3) emphasised new global trends in tourism and how they impact higher education. Luka and Donina's (2012) research was focused on skills and competencies that have to be enhanced in order to operate in the tourism business. Tourism students and employers evaluated the skills, abilities and attitudes in order to improve curricula design. This paper extends their study and focuses on the evaluation of creativity. Current research is a pilot study for the full-scale examination involving students from all tourism programs of Latvia.

The objective of this study is to provide the research base for the full-scale analysis through developing a tool for creativity evaluation. In order to attain this objective the author has reviewed literature and identified underlying variables used to measure creativity.

\section{THEORETICAL FRAMEWORK}

Creativity is an essential issue for a tourism business specialist. As a business field tourism specialists need to possess the same skills and abilities as an entrepreneur or manager. Gibb described the skills an entrepreneur or manager must have (1998, p. 6-8). Two of them are very close to creativity. They are: 1) intuitive decision making - the skill to take decisions based upon 
judgment with limited formal information, 2) creative problem solving - finding innovative ways of dealing with major problems.

Lumsdaine and Lumsdaine $(1995$, p. 245$)$ proceed to provide a process for decision-making that is parallel to a creative problem-solving process. Decision-making can be defined as selecting a course of action to achieve a desired purpose (Lumsdaine, \& Lumsdaine, 1995, p. 241). Entrepreneurs need to develop a balance between making decisions based on past experiences and keeping their minds open to new possibilities. In order to bridge the gap between identifying opportunities and solutions to problems and implementing them it is critical for managers to obtain creative decision-making skills.

Combining the creative factors researchers at the University of Valencia have conducted a similar research into creativity in an effort to promote creativity and innovation through an Educational Model for Creative Development (PECEI). The PECEI model includes the following criteria: inventiveness; an ability to project development, the ability to use outside ideas; ideas have to manifest, be developed, tested, evaluated and modified; the ability to escape the typical dominant idea; stimulation, intuition, direction and perseverance; divergent and critical thinking (Fields, \& Bisschoff, 2014, p. 23-31).

Elaborating this model Fields and Bisschoff surveyed 500 students and the majority of them were from the Faculty of Economic and Management (Fields, \& Bisschoff, 2014, p. 25-26). Based on four theoretical models for creativity assessment (PECEI, Torance Test of Creative Thinking, the conceptual map of creativity in teaching and learning, Amusement Park Theoretical Model) a twelve factor model was created and it resulted in acceptable reliability. These factors are: challenging the status quo, detachment, synthesis, cognition, association and communication, awareness, similarity, external motivation, sensitivity, experimenting and combining, dimensional thinking and problem solving (Fields, \& Bisschoff, 2014, p. 27-30). The model assumes that creativity involves a set of attributes and thinking skills. The model can be used for developing creativity and can be seen as a model with a measurement tool for judging the educational quality of creativity. This model is important to consider in the development of a structural framework to measure creativity at tertiary educational level because it identifies indicators of creativity and offers insight into the measurement of creativity.

Other important variables have been found in Proctor's study (1991, p. 223-230). He assumed that creativity contributes to all areas and activities of management. It helps to use more efficiently the manager's time, to find new ways to motivate employees, to appeal to customers' wants and needs, to find new production and marketing methods, to identify new product-market opportunities etc.

Summarizing the literature review the author determined nineteen creativity attributes applied for the research design (Appendix 1). 


\section{RESEARCH METHODOLOGY}

This paper is aimed at detecting the factors for creativity evaluation, test them and provide implications for further studies. Quantitative methods have been applied due to the further-going large-scale research (Saunders, Lewis \& Thornhill, 2009, p. 482). The survey design is based on the following research questions:

1. What creativity attributes are important for operating in tourism business?

2. How creativity attributes are enhanced in the tourism programs?

Thereby creativity attributes elaborated from the literature review have been converted into a questionnaire (Saunders, Lewis, \& Thornhill, 2009, p. 371-373). Except general information, the questionnaire consisted of three parts: importance of creativity in tourism industry, creativity enhancement and students' self-evaluation. Each part contained 19 Likert scale questions asking to evaluate creativity attributes from 1 (very low) to 5 (very high). The questionnaire was randomly distributed in Turiba University among students of tourism programs (EQF level 6, 7 programs) during February 2016. The total size of the research population was 996 students. At this stage of the research 31 responses were received. The results of the study on a small sample will be later compared with the full-scale survey. The sample was composed by local (58.1\%) and international students (41.9\%) studying Tourism and Hospitality Management (54.8\%), Event and Leisure Management $(16.1 \%)$ and Strategic Tourism Management (29.1\%) programs. Four groups by the highest level of education completed were targeted: secondary school/gymnasium/vocational school (45.2\%), college (22.6\%), bachelor level (19.4\%) and master level (12.9\%). Three groups were determined in terms of work experience: less the one year (22.6\%), from 1 to 5 years $(58.1 \%)$ and from 6 to 10 years (19,. \%).

Quantitative research software SPSS Statistics 22.0 has been applied for data analysis based on descriptive and inferential statistics analysis provided by Curwin and Slater (2007). In order to reveal the differences and similarities between samples non-parametric tests were applied due to the not normally distributed data (Baggio, \& Klobas, 2011, p. 23-24). Data validity and reliability was verified by Cronbach's Alpha test.

\section{RESULTS AND DISCUSSION}

This research is a part of the study on creativity in tourism curricula involving the opinion of all stakeholders in the process. Data regarding educators and employers' opinions had been collected earlier. This stage of the research is characterized by the investigation of the students' view. 


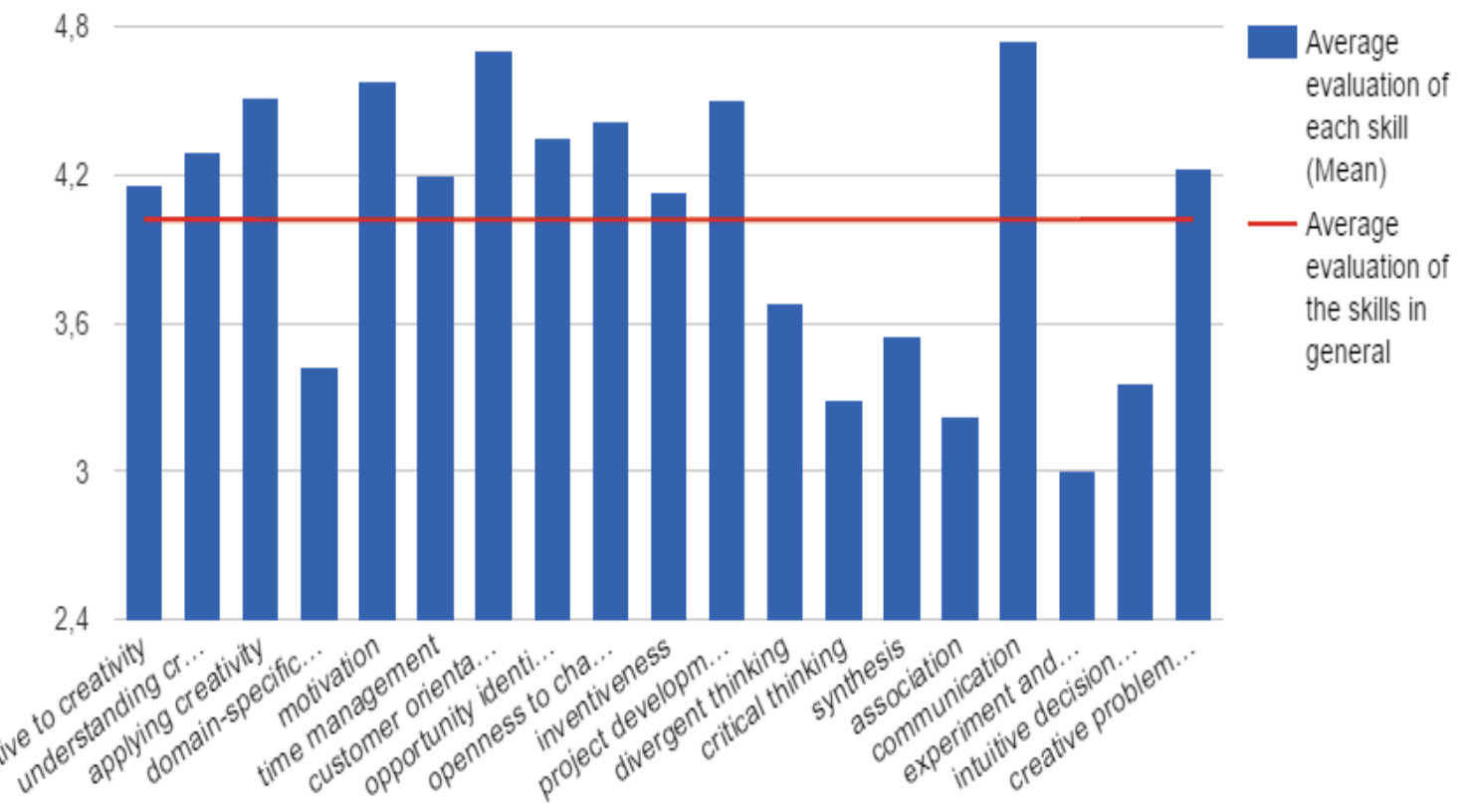

Figure 1. Students' opinion regarding the importance of creativity attributes for operation in tourism.

Source: Own chart.

Firstly, the students evaluated the importance of creativity attributes for operation in tourism. The results of evaluation (means) are presented in Figure 1 (refer to Figure 1). The highest evaluation has been given to Communication (mean 4.7419, sum 147), Customer Orientation (mean 4.709, sum 146), Motivation (mean 4.5806, sum 142), Applying Creativity (mean 4.5161, sum 140) and Openness to Changes (mean 4.4194, sum 137). These findings correspond to tourism managers' opinion in terms of abilities and competences necessary for tourism specialists to successfully operate in the labour market (Perederenko, 2016a). The fact that eleven out of nineteen attributes have got the maximum scale in most cases (modes 5 ) has significance for this study. On average the evaluation of the importance of creativity is high (4. 018). It correlates with the evaluation done earlier by educators from Turiba University (Perederenko, 2016b). The majority of them rated creativity as important (48.5\%) and very important (36.4\%).

Students gave the lowest rank to Experiment and Combination (mean 3, sum 93), Association (mean 3,2258, sum 100), Critical Thinking (mean 3,2903, sum 102), Intuitive Decision Making (mean 3,3548, sum 104) and Domain-Specific Creativity (mean 3,4194, sum 106). It is important that only these five attributes scored by 3 in the most cases (modes 3 ). The description of these terms should be reviewed and tested by educators or experts. 


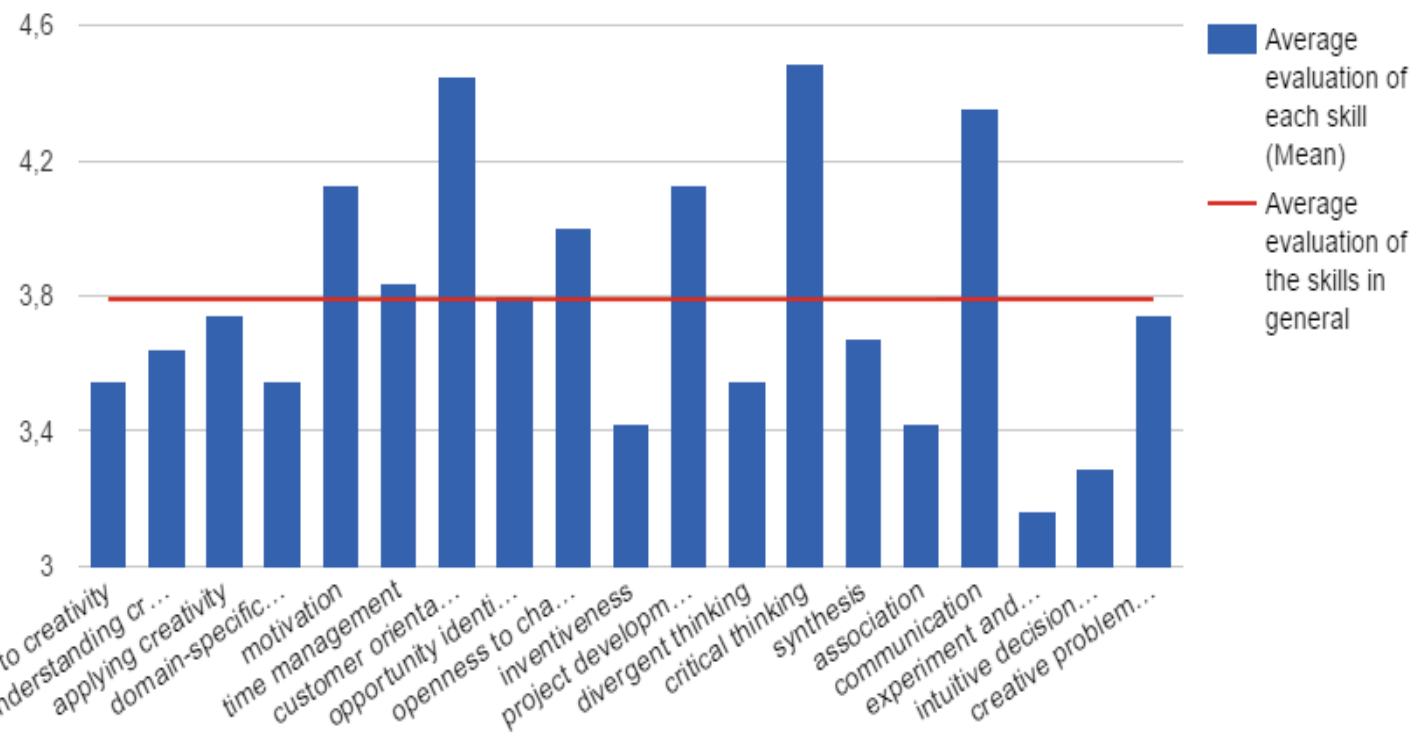

Figure 2. Students' opinion regarding the enhancement of creativity attributes in the tourism programs.

Source: Own chart.

The next part of the evaluation is connected with the enhancement of creativity attributes in the programs students studied (refer to Figure 2). The average results of this evaluation are closer to high than medium (3.79) which is higher than the medium level given by educators (78.8\%) (Perederenko, $2016 \mathrm{~b}$ ). The highest evaluations have been given to Critical Thinking (mean 4.4839, sum 139), Communication (mean 4.3454, sum 135), Customer Orientation (mean 4.709, sum 138), Motivation (mean 4.129, sum 128) and Project Development (mean 4.129, sum 128).

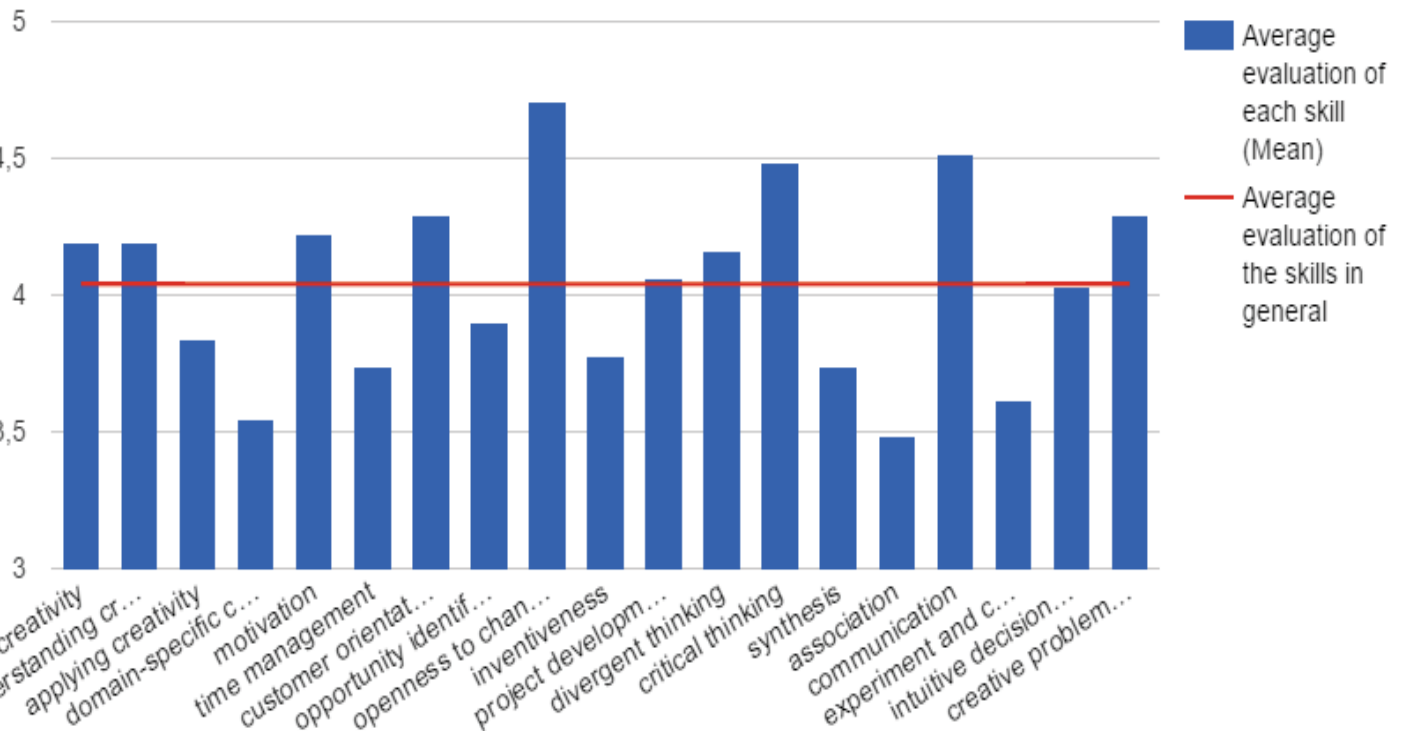

Figure 3. Students' self-evaluation of creativity attributes.

Source: Own chart. 
An important issue from these results is the fact that four most highly enhanced attributes have been ranked as very important. More significant inequality of the ratings can be found on Figure 2 compared to Figure 1. In terms of enhancement, students twice as frequently gave 3 points (8 from 19) than 5 (4 from 19).

Proceeding to Figure 3 (refer to Figure 3), the average self-evaluation of creativity attributes done by students (4.04) is very close to average importance evaluation. Comparing the results of these three evaluations (refer to Table 1) the three attributes to be more highly enhanced are: Applying Creativity, Understanding Creativity and Opportunity Identification.

Table 1. Comparative table of ranks done by students regarding the importance of the attributes in tourism: their enhancement in the study programs and self-evaluation.

\begin{tabular}{|l|l|l|l|}
\hline Attributes & Importance rank & Enhancement rank & Self-evaluation rank \\
\hline Communication & 1 & 3 & 2 \\
\hline customer orientation & 2 & 2 & 4 \\
\hline Motivation & 3 & 4 & 5 \\
\hline applying creativity & 4 & 7 & 11 \\
\hline openness to changes & 5 & 5 & 1 \\
\hline opportunity identification & 6 & 8 & 10 \\
\hline understanding creativity & 7 & 9 & 6 \\
\hline
\end{tabular}

Source: Developed by the author.

In order to test data validity and reliability Cronbach's Alpha test by SPSS software was applied. Cronbach's Alpha test verifies a high validity and acceptable internal consistency $(\alpha=0.759)$ as well as acceptable data reliability $(\alpha=0.742-771)$.

Kolmogorov-Smirnov $\mathrm{Z}$ test was applied to determine empirical distribution. The results of the test applied show that the data do not have normal distribution as p-value $=0.000$ which is $<0.05$. Therefore, non-parametric tests were chosen for further data analysis.

The difference between the opinion of two groups - local and international students was tested by Mann-Whitney $U$ test. The data indicated that there is no significant difference between opinions of the groups compared in terms of all three questions: $p$-value $=0.082-0.984$, which is $<0.05$. Thus, the obtained results may be generalized.

Following the difference analysis the data were examined by Kruskal Wallis test according to three categories: the highest level of education completed, the general work experience and the study program (Baggio, \& Klobas, 2011, p. 24). Several significant differences were found during the study (refer to Tables 2, 3, 4), where:

$$
\left(\chi^{2}(1)=6.058-11.259 ; p=0.002-0.048\right) \text {. }
$$


Firstly, the difference between opinions in terms of education level has been studied. The most significant distinction have been found in the evaluation of Creative Problem Solving between bachelor (mean rank 23.17) and master (6.50) students (refer to Table 2).

Table 2. Significant differences between opinions of students in terms of the highest education level.

\begin{tabular}{|l|l|}
\hline Variable & p-value \\
\hline importance of understanding creativity & 0.041 \\
\hline importance of motivation & 0.022 \\
\hline enhancement of understanding creativity & 0.041 \\
\hline enhancement of openness to changes & 0.008 \\
\hline enhancement of project development & 0.031 \\
\hline enhancement of divergent thinking & 0.046 \\
\hline enhancement of creative problem solving & 0.002 \\
\hline evaluation of project development & 0.009 \\
\hline evaluation of association & 0.004 \\
\hline
\end{tabular}

Source: Developed by the author.

Similar differences could be seen also in the results regarding enhancement of Understanding Creativity, Openness to Changes, Project Development and Divergent Thinking, where the mean rank of evaluation made by bachelors (15.25-25.58) is much higher than that by masters (5.25-13.13). It means that the level of education completed could influence criticality regarding the enhancement. Very high difference is in the position of self-evaluation of Project Development. Higher education level means higher self-evaluation of the creativity.

The next table (refer to Table 3) shows several important issues. Among three study programs significant differences have been found between the students studying Tourism and Hospitality Management and Strategic Tourism Management (MBA). MBA students were more critical towards the importance of Initiative to Creativity, Understanding Creativity, Motivation, Time Management. In Tourism and Hospitality Management study program attention should be paid to the enhancement of Project Development and Synthesis. There is a significant difference between the evaluation done by students of the last program mentioned (mean rank 11.91-12.53) and the other two programs (mean rank 19.30-21.00). The implications of these results to further research are to analyse deeper factors in order to explain these differences. It also could be explained by the numbers of students in the groups. Usually, study groups are larger in Tourism and Hospitality Management program. This fact could influence the collaboration and team-work which are important conditions for the development of these attributes. 
Table 3. Significant differences between the opinion of students in terms of the study program.

\begin{tabular}{|l|l|}
\hline Variable & $\mathrm{p}$-value \\
\hline importance of initiative to creativity & 0.016 \\
\hline importance of understanding creativity & 0.009 \\
\hline importance of motivation & 0.003 \\
\hline importance of time management & 0.01 \\
\hline enhancement of understanding creativity & 0.016 \\
\hline enhancement of time management & 0.043 \\
\hline enhancement of project development & 0.035 \\
\hline enhancement of synthesis & 0.013 \\
\hline evaluation of time management & 0.036 \\
\hline evaluation of project development & 0.003 \\
\hline
\end{tabular}

Source: Developed by the author.

Table 4. Significant differences between the opinion of students in terms of the work experience.

\begin{tabular}{|l|l|}
\hline Variable & $\mathrm{p}$-value \\
\hline importance of understanding creativity & 0.039 \\
\hline importance of time management & 0.023 \\
\hline importance of experiment and combination & 0.002 \\
\hline enhancement of understanding creativity & 0.001 \\
\hline enhancement of opportunity identification & 0.015 \\
\hline enhancement of association & 0.048 \\
\hline enhancement of experiment and combination & 0.047 \\
\hline enhancement of creative problem solving & 0.009 \\
\hline evaluation of domain-specific creativity & 0.034 \\
\hline evaluation of project development & 0.012 \\
\hline evaluation of experiment and combination & 0.004 \\
\hline
\end{tabular}

Source: Developed by the author.

The last table of Kruskal-Wallis test results (refer to Table 4) contained the largest number of differences. There are also some similarities with the above tables. It could be explained that those studying Strategic Tourism Management have higher education level and work experience. Their lower evaluation of Understanding Creativity, Time Management and Experiment and Combination have high significance for the study. Thus, it also could explain the lower evaluation of the enhancement of these attributes.

Evaluation of Project Development is in all three tables. This fact means that some special activities should be offered for those who don't have rich education and experience.

Wilcoxon Signed ranks test was applied to find out if the enhancement of the attributes impact self-evaluation of students. The data show that there is no significant difference in most cases except seven factors $(\mathrm{p}$-value $=0.000-0.015)$. They are Initiative to Creativity, Understanding Creati- 
vity, Openness to Changes, Divergent Thinking, Experiment and Combination, Intuitive Decision Making and Creative Problem Solving. It could mean that these attributes are enhanced little.

\section{CONCLUSION}

Summarizing all results received the answers to the research questions could be provided. First of all, in the students' opinion creativity has high importance for the operation in tourism business. Just a few indicated medium important. Moreover, the average importance level ranked by students is higher than made by educators. The most important attributes are Communication, Customer Orientation, Motivation, Applying Creativity, Openness to Changes, Understanding Creativity and Opportunity Identification.

Answering on the second research question regarding the enhancement of creativity attributes in the programs students studied, the average results of this evaluation are higher than medium. The highest evaluations have been given to Critical Thinking, Communication, Customer Orientation, Motivation and Project Development. There are significant differences between enhanced and lower enhanced attributes. Initiative to Creativity, Understanding Creativity, Openness to Changes, Divergent Thinking, Experiment and Combination, Intuitive Decision Making and Creative Problem Solving identified as the attributes with low both enhancement and evaluation rank. Moreover, Applying Creativity and Opportunity Identification also should be enhanced higher.

Furthermore, several implications for further research have been found. Education level and the work experience have negative influence on the opinion regarding importance and enhancement of the creativity. Master students were more critical towards the importance of Initiative to Creativity, Understanding Creativity, Motivation, Time Management. Higher education level and higher experience is subject to lower evaluation of importance but higher self-evaluation. In Tourism and Hospitality Management study program attention should be paid to Project Development and Synthesis enhancement.

\section{REFERENCES}

[1] Baggio, R., \& Klobas, J. (2011). Quantitative Methods in Tourism. A Handbook. Bristol: Channel View Publications.

[2] Curwin, J., \& Slater, R. (2007). Quantitative Methods for Business Decisions, $6^{\text {th }}$ edition. Andover: Cengage Learning EMEA.

[3] Fields, Z., \& Bisschoff, C., A. (2014). Developing and Assessing a Tool to Measure the Creativity of University Students. Journal of Social Science, 38(1). 23-31.

[4] Gibb, A., A. (1998). Educating Tomorrows Entrepreneurs. Economic Reform Today, 4, 1-10.

[5] Johnson, S., Veitch, S., \& Devianti, S. (2015). A framework to embed communication skills across the curriculum: A design-based research approach, Journal of University Teaching $\mathcal{E}$ Learning Practice, 12(4). 1-14.

[6] Khan, M., A., \& Law, L., S. (2015). An Integrative Approach to Curriculum Development in Higher Education in the USA: A Theoretical Framework, International Education Studies, 8 (3). 66-76. 
[7] Kiralova, A. (2014). New Trends in Tourism - a Challenge for Modernization of Tourism Higher Education in the Czech Republic, Skyline Business Journal, 10 (1), 1-8.

[8] Leuven Communiqué. (2009). Retrieved from http://www.ond.vlaanderen.be/hogeronderwijs/bologna/conference/documents/leuven_louvain-la-neuve_communiqu\%C3\% A9_ april_2009.pdf.

[9] Luka, I., \& Donina, A. (2012). Challenges of Tourism Education: Conformity of Tourism Curriculum to Business Needs, Academica Turistica, 1, 85-101.

[10] Lumsdaine, M., \& Lumsdaine, E. (1995). CPS Thinking skills for A Changing World; Columbus: McGraw-Hill Education, 220.

[11] OECD (2015). OECD Innovation Strategy 2015: An agenda for policy action. Online, Retrieved from https:// www.oecd.org/sti/OECD-Innovation-Strategy-2015-CMIN2015-7.pdf.

[12] Perederenko, K. (2016a). Creativity in Tourism for Business Competitiveness, paper accepted to XVII International Scientific Conference Competitive Enterprises in a Competitive Nation, Riga: Turiba University.

[13] Perederenko, K. (2016b). Importance of Creativity in Non-art Education, paper accepted to the 9th Interdisciplinary Conference of the University Network of the European Capitals of Culture, Pilsen: West Bohemia University.

[14] Proctor, R., A. (1991). Can Computers Simulate Managerial Creativity? Leadership \& Organization Development Journal, 12 (4), 13 - 16.

[15] Saleh, H., M., Y., Hashim, M., Yaacob, R., B., \& Kashim, A., J., A., Y. (2015). Curriculum Assessment in Social Sciences at Universiti Pendidikan Sultan Idris, Journal of Education and Practice, 6 (22). 48-54.

[16] Saunders, M., Lewis, P., \& Thornhill, A. (2009). Research methods for business students, $5^{\text {th }}$ edition. Edinburgh: Pearson Education.

[17] Styhre, A., \& Sundgren, M. (2005). Managing Creativity in Organizations. Critique and Practices. London: Palgrave Macmillan UK.

[18] Tom-Lawyer, O., O. (2015). Lecturers' Perceptions of the Implementation of the Revised English Language Nigeria Certificate in Education Curriculum. Journal of Education and Practice, 6 (12), 181-193.

[19] Yerevan Communiqué. (2015). Retrieved from http://www.ehea.info/Uploads/SubmitedFiles/5_2015/112705.pdf. 


\section{APPENDICES}

\section{APPENDIX 1. CREATIVITY ATTRIBUTES}

\begin{tabular}{|c|c|c|}
\hline Attribute & Source & Explanation \\
\hline Initiative to creativity & $\begin{array}{l}\text { Fields \& Bisschoff (2014), } \\
\text { Perederenko (2016a) }\end{array}$ & $\begin{array}{l}\text { an individual's willingness and motivation to } \\
\text { challenge assumptions and take initiative }\end{array}$ \\
\hline $\begin{array}{l}\text { Understanding } \\
\text { creativity }\end{array}$ & Fields \& Bisschoff (2014) & ability to look at the big picture of creativity \\
\hline Applying creativity & Fields \& Bisschoff (2014) & $\begin{array}{l}\text { being creative in an environment that tears } \\
\text { down personal barriers to creative thinking and } \\
\text { being motivated to be creative in his/her own } \\
\text { interest areas }\end{array}$ \\
\hline $\begin{array}{l}\text { Domain-specific } \\
\text { creativity }\end{array}$ & Perederenko (2016a) & $\begin{array}{l}\text { the skills to find creative solutions based on } \\
\text { specific industry knowledge }\end{array}$ \\
\hline Motivation & $\begin{array}{l}\text { Perederenko (2016a), } \\
\text { Proctor (1991) }\end{array}$ & $\begin{array}{l}\text { the ability to find new way to motivate } \\
\text { employees or colleagues }\end{array}$ \\
\hline Time management & Proctor (1991) & the skills to use more efficiently manager's time \\
\hline Customer orientation & Proctor (1991) & $\begin{array}{l}\text { the ability to appeal to customers' wants and } \\
\text { needs }\end{array}$ \\
\hline $\begin{array}{l}\text { Opportunity } \\
\text { identification }\end{array}$ & $\begin{array}{l}\text { Lumsdaine and } \\
\text { Lumsdaine (1995), Proctor } \\
\text { (1991) }\end{array}$ & $\begin{array}{l}\text { the ability to identify new product-market } \\
\text { opportunities }\end{array}$ \\
\hline Openness to changes & $\begin{array}{l}\text { Lumsdaine and } \\
\text { Lumsdaine (1995), } \\
\text { Perederenko (2016a) } \\
\end{array}$ & $\begin{array}{l}\text { the ability to accept changes and deal with the } \\
\text { changes }\end{array}$ \\
\hline Inventiveness & $\begin{array}{l}\text { Fields \& Bisschoff (2014), } \\
\text { Proctor (1991) }\end{array}$ & $\begin{array}{l}\text { the ability to generate new ideas, solutions, find } \\
\text { new production and marketing methods etc }\end{array}$ \\
\hline Project development & Perederenko (2016a) & the skills to project development \\
\hline Divergent thinking & $\begin{array}{l}\text { Fields \& Bisschoff } \\
\text { (2014), Lumsdaine and } \\
\text { Lumsdaine (1995) } \\
\end{array}$ & $\begin{array}{l}\text { the ability to see different aspects of a problem, } \\
\text { the ability not to get stuck on a set of rules to } \\
\text { solve a problem }\end{array}$ \\
\hline Critical thinking & $\begin{array}{l}\text { Fields \& Bisschoff } \\
\text { (2014), Lumsdaine and } \\
\text { Lumsdaine (1995) }\end{array}$ & $\begin{array}{l}\text { the ability to recognize gaps and contradictions } \\
\text { in existing knowledge }\end{array}$ \\
\hline Synthesis & Fields \& Bisschoff (2014) & $\begin{array}{l}\text { the ability to combine concepts to find creative } \\
\text { solutions }\end{array}$ \\
\hline Association & Fields \& Bisschoff (2014) & $\begin{array}{l}\text { the ability to generate new ideas by looking } \\
\text { actively for associations among concepts, the } \\
\text { use of brainstorming to make associations }\end{array}$ \\
\hline Communication & Fields \& Bisschoff (2014) & $\begin{array}{l}\text { to propose new ideas regularly through } \\
\text { communication and the ability to persuade } \\
\text { others that creative ideas generated are } \\
\text { valuable }\end{array}$ \\
\hline $\begin{array}{l}\text { Experiment and } \\
\text { combination }\end{array}$ & Fields \& Bisschoff (2014) & $\begin{array}{l}\text { the ability to find the best creative solution by } \\
\text { experimenting and combining objects }\end{array}$ \\
\hline $\begin{array}{l}\text { Intuitive decision } \\
\text { making }\end{array}$ & Gibb (1998) & $\begin{array}{l}\text { the skill to take decisions based upon judgment } \\
\text { with limited formal information }\end{array}$ \\
\hline $\begin{array}{l}\text { Creative problem } \\
\text { solving }\end{array}$ & $\begin{array}{l}\text { Gibb (1998), Lumsdaine } \\
\text { and Lumsdaine (1995) }\end{array}$ & $\begin{array}{l}\text { the ability to find innovative ways of dealing } \\
\text { with major problems }\end{array}$ \\
\hline
\end{tabular}

